\title{
Efficacy of curcumin in inducing apoptosis and inhibiting the expression of VEGF in human pterygium fibroblasts
}

\author{
CHENG-WEI LU ${ }^{1}$, JI-LONG HAO ${ }^{1}$, LEI YAO ${ }^{2}$, HAI-JUN LI $^{3}$ and DAN-DAN ZHOU ${ }^{4}$ \\ Departments of ${ }^{1}$ Ophthalmology and ${ }^{2}$ Dermatology, The First Hospital of Jilin University; \\ ${ }^{3}$ Translational Medicine Research Institute, The First Hospital of Jilin University; ${ }^{4}$ Department of Radiology, \\ The First Hospital of Jilin University, Changchun, Jilin 130021, P.R. China
}

Received December 7, 2015; Accepted March 27, 2017

DOI: $10.3892 /$ ijmm.2017.2944

\begin{abstract}
Pterygium is an inflammatory and degenerative ocular surface disease, in which the conjunctiva on the cornea grows to form a fibrous tissue in the shape of a triangle. Although pterygium surgery is used broadly in clinical practice, its high recurrence rate poses a great concern for patients and doctors. In the present study, we examined the effects of curcumin on the apoptosis and proliferation of human pterygium fibroblasts (HPFs) in an in vitro culture system. HPFs were incubated with curcumin for 24 to $72 \mathrm{~h}(5,20,80$ or $200 \mu \mathrm{mol} / \mathrm{l})$. The proliferation-inhibiting effects of curcumin were assayed by MTT assay at different time points and at various concentrations. The expression of vascular endothelial growth factor (VEGF) in each group was detected by RT-qPCR and ELISA. The apoptotic effects of curcumin were detected by flow cytometry (FCM). Treatment with curcumin at $80 \mu \mathrm{mol} / 1$ for $48 \mathrm{~h}$ significantly inhibited HPF proliferation. Curcumin significant induced the apoptosis of HPFs. Our findings thus suggest that curcumin suppress cell proliferation in the pterygium by inducing HPF apoptosis and inhibiting VEGF expression. Thus, curcumin has potential for use as a novel agent for the treatment of pterygium in the near future.
\end{abstract}

\section{Introduction}

Pterygium is an inflammatory and degenerative ocular surface disease in which the conjunctiva on the cornea grows to form fibrous tissue in the shape of a triangle (Fig. 1). Pterygium has a worldwide distribution though it is considered more common in warm, dry climates with a reported prevalence as high as $22 \%$ in equatorial areas and less than $2 \%$ in latitudes above 40 degrees (1). It is speculated to be associated with corneal and

Correspondence to: Dr Hai-Jun Li, Translational Medicine Research Institute, The First Hospital of Jilin University, 71 Xinmin Street, Changchun, Jilin 130021, P.R. China

E-mail: hjli2012@jlu.edu.cn

Mrs. Dan-Dan Zhou, Department of Radiology, The First Hospital of Jilin University, 71 Xinmin Street, Changchun, Jilin 130021, P.R. China E-mail: zhoudan0928@sohu.com

Key words: curcumin, human pterygium fibroblasts, apoptosis conjunctival microtrauma from exposure to sunlight and/or dust. A higher prevalence of pterygium has been recorded among outdoor workers as compared to indoor workers in Nigeria, South India and Southwest China (2-4). The pathogenesis of the disease is not yet completely understood; however, recent evidence suggests that pterygium is histologically composed of proliferating fibrovascular tissue and is correlated strongly with exposure to ultraviolet (UV) radiation (5-7). Inflammation and fibrovascular proliferation may be other factors associated with the occurrence of pterygium. DNA damage has been reported to initiate pterygium development. Hereditary predisposition may be the underlying factor in the occurrence of pterygium (8). UV light has been shown to induce the activation of pro-inflammatory cytokines, chronic inflammatory cells and growth factors. It may also damage DNA in predisposed individuals. However, the integration of factors associated with the occurrence of pterygium has not yet been reported $(9,10)$. Furthermore, evidence indicates that vascular endothelial growth factor (VEGF) and basic fibroblast growth factor (bFGF) expression is increased in pterygium (11-13). Therefore, these growth factors may be directly or indirectly involved in the pathogenesis of pterygium. Pterygium fibroblasts are tumour-like transformed cells that grow much more rapidly in medium without high concentrations of serum and can grow in a semisolid agar in contrast to normal fibroblasts (14). Surgical excision is the firstchoice treatment for pterygium; however, the high recurrence rate is a burden for patients. Therefore, the treatment of pterygium remains quite controversial. The identification of effective drugs for the treatment of pterygium is urgently required.

Curcumin is a yellow-coloured polyphenol that is isolated from the plant, Curcuma longa, and is the principal curcuminoid of the popular spice, turmeric. Curcumin has been widely studied for its antioxidant, anti-inflammatory, anti-angiogenic and wound-healing effects $(15,16)$. Curcumin has been shown to exert antitumour effects that are mediated by a wide variety of mechanisms both in vitro and in vivo. Curcumin inhibits the proliferation and induces the apoptosis of a variety of cancer cell types in vitro, including cells from cancers of the breast, prostate, lung, pancreas, ovary, bladder, cervix, head and neck, brain, kidney and skin (16-26). A previous study demonstrated that curcumin significantly inhibited the proliferation of HPFs, which resulted in the arrest of HPFs in the G0/G1 phase (27). However, the apoptosis of HPFs and the VEGF pathway was not 
examined. The purpose of the present study was to investigate the inhibitory effects of curcumin on human pterygium fibroblasts (HPFs) in vitro. To the best of our knowledge, this study is the first to examine the inhibitory effects of curcumin on the expression of VEGF in HPFs. The two studies coordinately investigate the effects of curcumin on the inhibition of HPFs.

\section{Materials and methods}

Reagents. Curcumin, RNase and MTT were purchased from Sigma-Aldrich (St Louis, MO, USA). Dulbecco's modified Eagle's medium (DMEM), trypsin, fetal bovine serum (FBS), PBS, penicillin and streptomycin were obtained from Gibco-BRL (Carlsbad, CA, USA). Propidium iodide (PI), Annexin V-FITC were purchased from BD Biosciences (San Jose, CA, USA).

Preparation of curcumin. Curcumin was dissolved in $0.05 \%$ DMSO to prepare a stock solution at a concentration of $10 \mathrm{mmol} / 1$ that was stored at $-20^{\circ} \mathrm{C}$. DMEM complete medium was added to dilute the curcumin to the appropriate concentrations prior to use.

Culture and passage of HPFs. The pterygium specimens were obtained from 5 female and 3 male patients, aged $54 \pm 8$ years, who underwent pterygium removal after they had provided written informed consent. The representative morphology of pterygium on the cornea shown in Figs. 1 and 2 was from a 52-year-old female patient. The present study was reviewed and approved by the Institutional Review Board of the First Hospital of Jilin University, Changchun, China. HPFs were cultured from explants of the fresh pterygium tissue from the surgical excision patients via a previously reported method (28). Briefly, the head of a fresh pterygium specimen was cut into small sections, washed in Hanks solution, and placed in a culture dish. DMEM with $15 \%$ FBS and gentamicin $(50 \mathrm{~g} / \mathrm{ml})$ was added to cover the explants (all from Gibco-BRL). The culture dish was placed in a $\mathrm{CO}_{2}$-regulated incubator in humidified $95 \%$ air $/ 5 \% \mathrm{CO}_{2}$ atmosphere overnight. Culture medium (identical to the first medium, but the concentration of FBS was reduced to $10 \%$ ) was added after the explants had adhered. In some cultures, epithelial cells also migrated from the explants in the early stage. However, epithelial cells rapidly became terminally differentiated and lost their viability in medium with high levels of serum and $\mathrm{Ca}^{2}$. Furthermore, during subculture, the fibroblasts detached from the well more easily compared to the epithelial cells. After the detachment of the fibroblasts was almost complete, serum was added to block the effect of the enzyme so that the epithelial cells remained in the well and could not be passed to the subculture. Therefore, only fibroblasts were present in the subcultures. The morphology of HPFs was examined using an Olympus microscope (serial no. 36048; provided by Olympus, Tokyo, Japan). The cells were cultured in DMEM complete medium and passaged for 3 to 7 generations. The stable cells were used in the following experiments.

Inhibitory effect of curcumin on HPF proliferation. The inhibitory effects of curcumin on the proliferation of HPFs were detected by MTT assays. All experiment steps were performed following the instructions of the kit instructions. Briefly, the cells were seeded on 96-well plates at a density of $5 \times 10^{3} / \mathrm{ml}$ at a volume of $200 \mu \mathrm{l} /$ well. All groups without or with curcumin $(5,20,80$ or $200 \mu \mathrm{mol} / \mathrm{l})$ were incubated for 24 to $72 \mathrm{~h}$. MTT $(1 \mathrm{mg} / \mathrm{ml})$ was added to each well, and the cells were incubated for $4 \mathrm{~h}$. The MTT solution was then aspirated, and $100 \mu \mathrm{l}$ of DMSO was then added. The 96-well plates were read using a microplate spectrophotometer (BioTek Synergy $\mathrm{H1}$; BioTek, Winooski, VT, USA) at $540 \mathrm{~nm}$. The experiments were repeated in triplicate. The inhibition percentage was calculated as follows: ( 1 - the value in experimental group/the value in the control group) $\mathrm{x} 100 \%$.

Flow cytometry (FCM) for cell apoptosis. Annexin V-FITC and PI double staining FCM analyses was carried out. The HPFs were plated in 96-well plates containing $200 \mu \mathrm{l}$ medium at a density of $5 \times 10^{3}$ cells/well. The induction of apoptosis in the HPFs was examined for the presence or absence of curcumin $(80 \mu \mathrm{mol} / \mathrm{l})$. After $48 \mathrm{~h}$ in culture, the HPFs were collected in $1.5 \mathrm{ml}$ centrifuge tubes, washed 3 times with cold PBS and binding buffer, and then stained with Annexin V-FITC and PI (Annexin V-FITC apoptosis detection kit; BD Biosciences) for apoptosis detection. Briefly, the HPFs in centrifuge tubes were first re-suspended in binding buffer. Subsequently, $5 \mu \mathrm{l}$ of Annexin V-FITC was added to the tubes, which were incubated for $10 \mathrm{~min}$ followed by the addition of $5 \mu \mathrm{l}$ PI. The samples were then incubated with PI for a further $15 \mathrm{~min}$ and immediately analysed using a flow cytometer (FACScan; BD Biosciences) with the FlowJo FACS analysis software. The cells in the different portions represented the different cell states as follows: the late apoptotic cells were present in the upper right portion, the viable cells were present in the lower left portion and the early apoptotic cells were present in the lower right portion.

$q P C R$. Total RNA was isolated from the HPFs using a Qiagen RNeasy Mini kit (Qiagen China Co., Ltd., Shanghai, China). Following the RNeasy Mini Kit instructions, $70 \%$ ethanol was added to the cell lysates or the homogenates and the samples were mixed by pipetting prior to being transferred to columns. Following centrifugation for $2 \mathrm{~min}$ at $4^{\circ} \mathrm{C}$ and $12,000 \mathrm{x}$ g, the flow-through extract was retained and stored on ice. RNA quality was assessed with an Agilent 2100 Bioanalyzer (Agilent Technologies GmbH, Waldbronn, Germany). cDNA was synthesized with SuperMix II reverse transcriptase using random hexamer primers (TransGen Biotech, Beijing, China) following the manufacturer's instructions. The primers for VEGF and GAPDH were designed and synthesized by the company, Sangon Biological Engineering Co., Ltd. (Shanghai, China). An Applied Biosystems StepOnePlus ${ }^{\mathrm{TM}}$ real-time PCR system was used to determine the mRNA levels of VEGF and GAPDH (internal control). The primer sequences for VEGF were as follows: sense, 5'-TGCCCACTGAGGAGTCCAAC-3' and antisense, 5'-TGGTTCCCGAAACGCTGAG-3'. The GAPDH primers were as follows: sense, 5'-CCAGGTGGTCTC CTCTGACTT-3' and antisense, 5'-GTTGCTGTAGCCAA ATTCGTTGT-3'. The reactions were performed using $3 \mu \mathrm{l}$ of cDNA in a $20 \mu \mathrm{l}$ reaction volume and the following thermal cycles profile: $10 \mathrm{sec}$ for pre-denaturation at $94^{\circ} \mathrm{C}, 5 \mathrm{sec}$ for denaturation at $94^{\circ} \mathrm{C}$ and $30 \mathrm{sec}$ for extension at $60^{\circ} \mathrm{C}$, for 40 cycles. The PCR products were $200 \mathrm{bp}$ in length. 


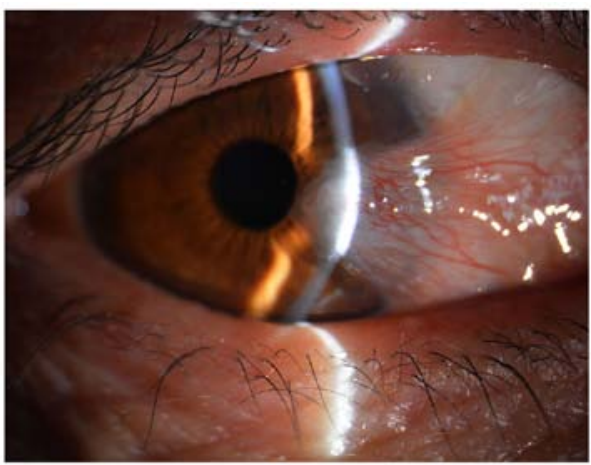

Figure 1. The morphology of pterygium on the cornea of a 52-year-old female patient.

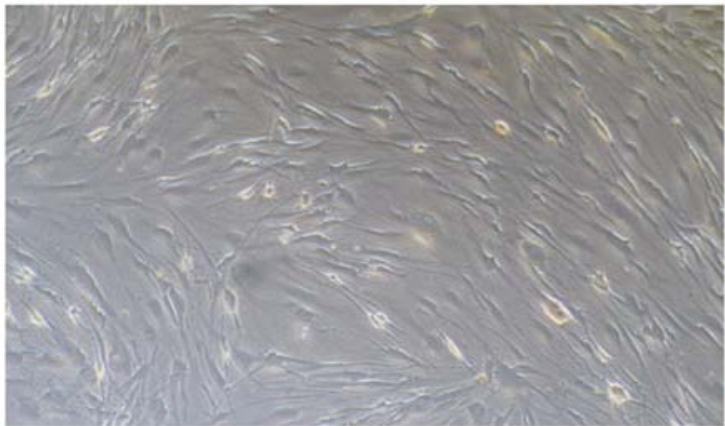

Figure 2. The morphology of human pterygium fibroblasts (HPFs). HPFs were cultured and characterized from explants of fresh pterygium tissue according to a previously described method by Yang et al (28). Cells from the 3 rd to the 7 th passages were used for the experiments.

Enzyme-linked immunosorbent assay (ELISA). The HPFs were plated at appropriate densities $\left(5 \times 10^{3}\right.$ cells/well) in 96-well plates. The culture supernatants were collected $48 \mathrm{~h}$ following incubation under each experimental condition without or with curcumin $(5,20,80$ or $200 \mu \mathrm{mol} / \mathrm{l})$. VEGF production was assessed using an ELISA kit (Abcam, Cambridge, MA, USA). The optical densities were measured at $450 \mathrm{~nm}$ on a microplate spectrophotometer (Multiskan MCC/340; Thermo Fisher Scientific, Inc., Pittsburgh, PA, USA) and the VEGF concentrations were determined based on a standard curve.

Statistical analysis. All data were analysed and assessed for significance using the D'Agostino-Pearson omnibus normality test. All data are presented as the means \pm the standard error of the mean. Mean values were compared using paired t-tests (2 groups) followed by the Bonferroni's correction for multiple comparison tests. P- values $<0.05$ were considered to indicate statistically significant differences. All statistical tests were performed using Prism software (GraphPad Software Inc., San Diego, CA, USA).

\section{Results}

Effects of curcumin on the proliferation of HPFs. Pterygium specimens were obtained from patients who underwent pterygium removal. HPFs were cultured from explants of fresh pterygium tissue from each surgical excision patient. The cells were cultured in DMEM complete medium and passaged for

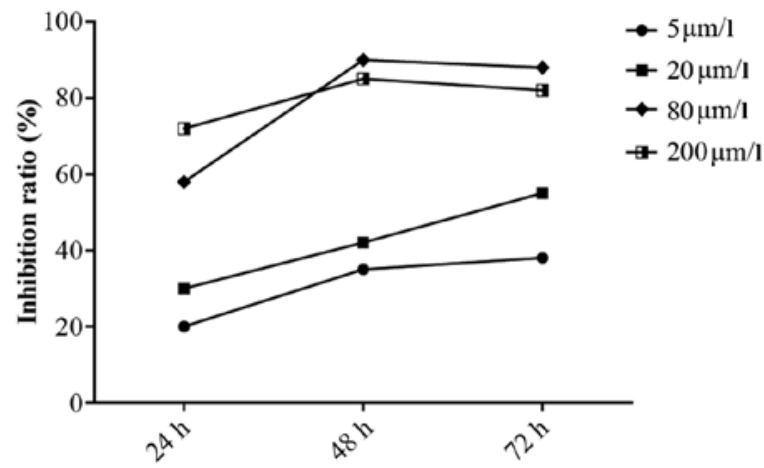

Figure 3. Rates of inhibition of human pterygium fibroblasts (HPFs) following treatment with various concentrations of curcumin.
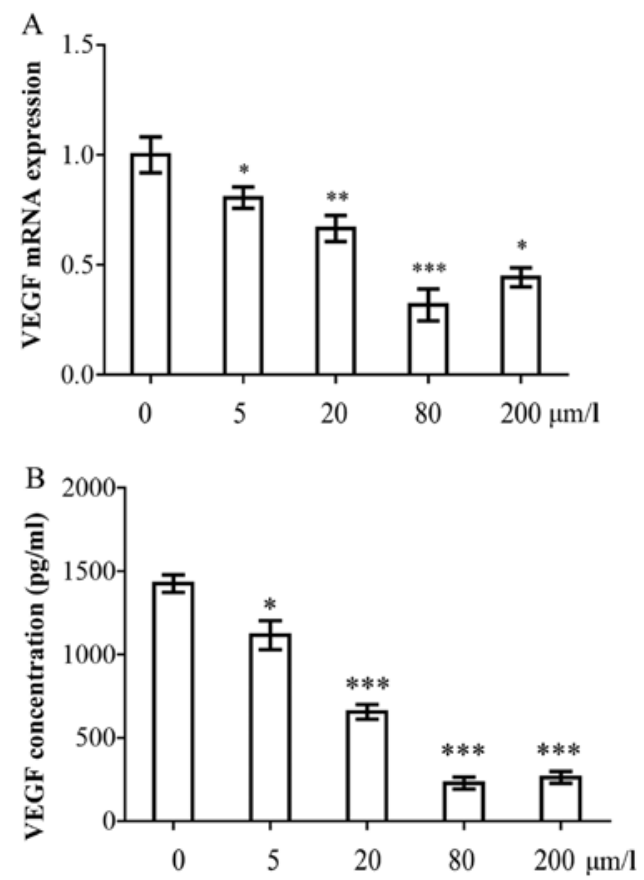

Figure 4. Curcumin inhibits the expression of vascular endothelial growth factor (VEGF) in human pterygium fibroblasts (HPFs). (A) qPCR analysis of VEGF mRNA expression in HPF cells treated with and without curcumin $(5,20,80$, and $200 \mu \mathrm{mol} / \mathrm{l})$. (B) VEGF concentrations in cell culture supernatants were detected with enzyme-linked immunosorbent assays (ELISA). The 2 experiments were repeated at least 3 times.

3 to 6 generations (Fig. 2). MTT assays revealed that curcumin significantly inhibited the proliferation of HPFs. The inhibitory effects of curcumin on HPFs were dose- and time- dependent within the ranges of 5-80 $\mu \mathrm{mol} / 1$ and 24-72 $\mathrm{h}$. Treatment with curcumin at $80 \mu \mathrm{mol} / 1$ for $48 \mathrm{~h}$ elicited the greatest inhibitory effect; this treatment inhibited the proliferation of HPFs with an inhibitory rate exceeding $90 \%$ compared with that of the blank control group $(\mathrm{P}<0.01)$. The time-effect curve is illustrated in Fig. 3.

Effects of curcumin on the expression of VEGF in HPFs. Based on the results of MTT assay, the cell pellets and cell culture supernatants were collected to detect the VEGF gene and protein concentrations $48 \mathrm{~h}$ following incubation under each experimental condition, either without or with curcumin $(5,20,80$ and $200 \mu \mathrm{mol} / \mathrm{l})$. As illustrated in Fig. 4A, the mRNA expres- 

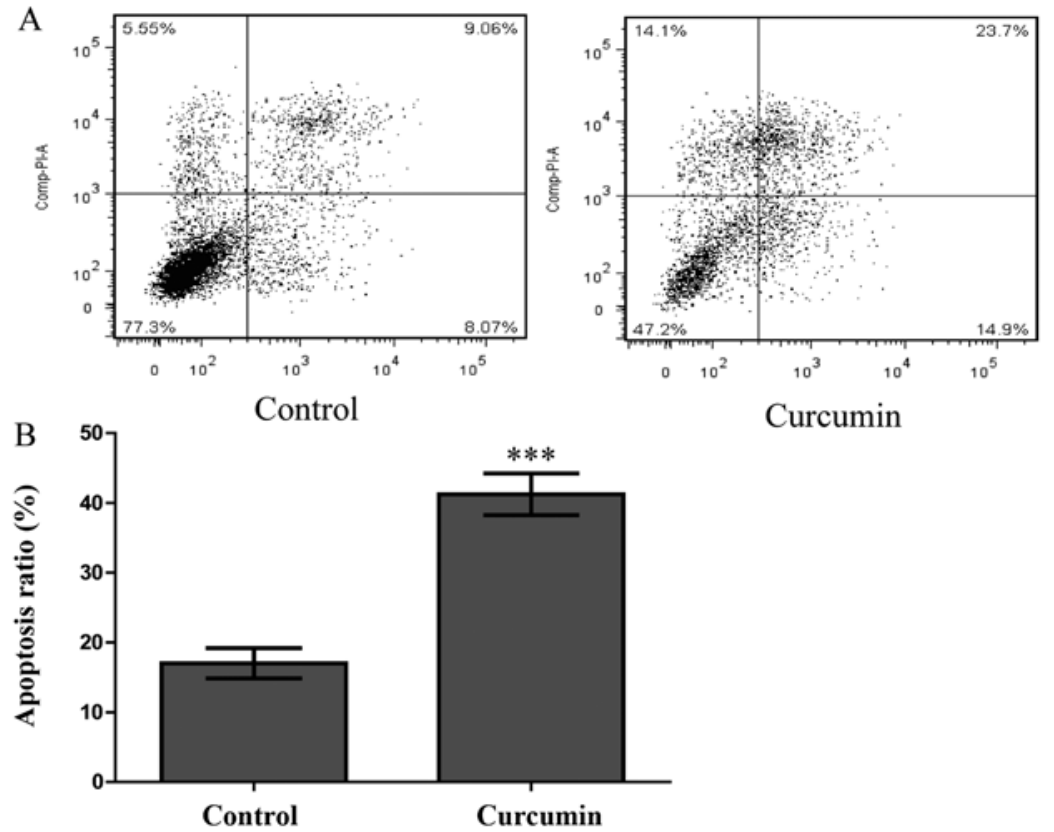

Figure 5. Apoptosis detection by flow cytometry (FCM) in human pterygium fibroblasts (HPFs) treated with curcumin. (A) FCM analysis of apoptosis in HPFs treated with curcumin. The cells were exposed to either control solution ( $0.1 \%$ DMSO in medium) or curcumin at $80 \mu \mathrm{M} / 1$ and incubated for $48 \mathrm{~h}$. The experiments were repeated at least 3 times. Upper left quadrant, necrotic cells; bottom left quadrant, viable cells; upper right quadrant, late apoptotic cells; lower right quadrant, early apoptotic cells. (B) Percentages of apoptotic cells. The apoptotic cells were calculated as the percentages of apoptotic cells in the upper right portion and the lower right portion relative to the total number of the cells. The data are expressed as the means \pm SDs of 3 experiments ${ }^{(* * *} \mathrm{P}<0.001 \mathrm{vs}$. control).

sion of VEGF in the curcumin-treated groups decreased by 0.80-0.42-fold compared with the control group $(\mathrm{P}<0.05)$. The inhibitory effects were dose-dependent. Subsequently, the VEGF concentrations in the cell culture supernatant following curcumin treatment, were investigated. The HPFs secreted large amounts of VEGF $(1,394.5 \pm 102.5 \mathrm{pg} / \mathrm{ml})$. However, the concentration of VEGF decreased significantly following treatment with curcumin. The VEGF concentrations were $1,120.5 \pm 75.5,720.2 \pm 64.5,180.3 \pm 35.2$ and $280.6 \pm 59.5 \mathrm{pg} / \mathrm{ml}$ following treatment with $5,20,80$ and $200 \mu \mathrm{mol} / 1$ curcumin, respectively (Fig. 4B). The inhibitory effects were dosedependent, and the $80 \mu \mathrm{mol} / \mathrm{l}$ curcumin concentration elicited the most potent inhibitory effect.

Annexin V-FITC andPIdouble staining assay. Toexplore whether curcumin also induces HPF apoptosis, an Annexin V-FITC and PI double staining assay was performed. HPFs were treated with curcumin at a concentration of $80 \mu \mathrm{mol} / 1$ for $48 \mathrm{~h}$ and were then analysed by FCM. As shown in Fig. 5A, compared with the control group, the numbers of early and late apoptotic cells increased significantly in the treated group. The proportion of early and late apoptotic cells in the curcumin-treatment group reached $38.6 \%$, which was greater than the proportion observed in the control group $(17.1 \%, \mathrm{P}<0.001$; Fig. 5B). This finding indicated that curcumin significantly induced HPF apoptosis.

\section{Discussion}

Pterygium is a common ocular surface disease that can cause loss of vision (28). The disorder may be characterized by cell proliferation, inflammatory processes, fibrosis, angiogenesis and the destruction of the extracellular matrix (29). Pterygium exhibits features that are similar to those of tumours, such as local invasion, metaplasia of epithelial cells, the presence of oncogenic viruses, the inactivation of tumour suppressor genes, and the loss of heterozygosity (30). Pterygium fibroblasts represent tumour-like transformed cells. Pterygium fibroblasts grow much more rapidly in medium without high concentrations of serum and can grow in a semisolid agar $(11,28)$. The pathogenesis of pterygium and its recurrence following surgical excision are not yet completely understood. The identification of a new drug that inhibits HPF proliferation would be of significance for the treatment of pterygium.

Curcumin is also known as diferuloylmethane and is obtained from Curcuma longa. Curcumin is regarded as a potent anticancer drug in relation to various types of tumour (31-34). Curcumin is extensively used in Ayurveda, Unani, Siddha and Chinese medicine for the management of various diseases and conditions, such as wounds, inflammation and cancer (35). The inhibition of tumour progression by curcumin primarily results from the downregulation of the expression of cancer formation and progression genes, such as p53, Egr-1 and c-Myc (36). Due to its ability to activate caspase-3 and cytochrome $c$ release, curcumin induces the apoptosis of seeral tumour cell lines, including HepG2, CRC, A549, HL60 and others (37). Angiogenesis is an important mechanism of tumour formation. Angiogenic factors include angiotensin, epidermal growth factor, bFGF, transforming growth factor (TGF) and VEGF. These factors play critical roles in tumour angiogenesis via their actions in cancerous tumour cells (38). The present study demonstrated that curcumin significantly inhibited the proliferation of HPFs based on the results of MTT assay. FCM revealed that curcumin increased the proportions of numbers of early and late apoptotic HPFs from 17.1 to $38.6 \%$. Our results revealed that curcumin suppressed cell proliferation via the apoptosis-inducing pathway. 
VEGF is a prominent pro-angiogenic and tumour growthpromoting hormone that is expressed in many types of tumour cells. The expression of VEGF is often obligatory for tumour angiogenesis; thus, the inhibition of the expression or biological function of VEGF has been fervently pursued as a cancer treatment (39). Tumorigenesis is a multistep process that is affected by tumour genes, cytokines, and the host immune system (40). During tumour development, VEGF is among the important factors that are involved in the growth, invasion and metastasis of the tumour (41). VEGF is secreted in greater amounts by HPFs than conjunctival fibroblasts (42). Since 2001, when the first hypothesis about the potential benefits of anti-VEGF therapy in human pterygium was proposed, controversies have continuously arisen based on published articles that have reported the use of bevacizumab as an adjuvant therapy for human pterygium $(43,44)$. Our findings demonstrate that the mRNA expression of VEGF in the curcumin-treated groups decreased by $0.8-0.42$-fold compared with the control group $(\mathrm{P}<0.05)$ and that the inhibitory effects were dose-dependent. HPFs can secrete large amounts of VEGF; however, the concentration of VEGF significantly decreased following treatment with curcumin. The inhibitory effects were dose-dependent, and the $80 \mu \mathrm{mol} / 1$ curcumin concentration elicited the most potent inhibitory effect.

Curcumin modulates the expression of VEGF via the inhibition of the JAK2/STAT3 pathway in laryngeal squamous cell carcinomas (45). Curcumin specifically targets the PI3K/ Akt/IKK signalling axis, which consequently leads to the concurrent, but independent suppression of both the NF- $\kappa \mathrm{B}$ and mTOR pathways, the concomitant activation of caspases, and the downregulation of VEGF. These events result in the induction of apoptosis, the prevention of angiogenesis, and ultimately the inhibition of adenoid cystic carcinoma progression (46). These mechanisms may represent novel targets for therapies. Therefore, our findings suggest that curcumin suppresses the proliferation of pterygium by inducing HPF apoptosis and inhibiting VEGF expression. To the best of our knowledge, this is the first study to demonstrate the inhibition of the expression of VEGF by HPFs by curcumin. However, additional studies on the molecular regulatory mechanisms are warranted to fully determine and understand the effects.

\section{Acknowledgements}

The present study was supported in part by grants from the Jilin Provincial Natural Science Foundation of China (no. 20140520014JH) and the 4th Young Scientists Fund of Jilin University (no. 2013068).

\section{References}

1. Viso E, Gude F and Rodríguez-Ares MT: Prevalence of pinguecula and pterygium in a general population in Spain. Eye (Lond) 25: 350-7, 2011

2. Achigbu E and Ezepue UF: Prevalence and severity of pterygium among commercial motorcycle riders in South Eastern Nigeria. Ghana Med J 48: 153-157, 2014.

3. Asokan R, Venkatasubbu RS, Velumuri L, Lingam V and George R: Prevalence and associated factors for pterygium and pinguecula in a South Indian population. Ophthalmic Physiol Opt 32: 39-44, 2012.
4. Zhong H, Chen Q, Li J, Shen W, Sheng X, Niu Z, Zhou H, Wei T, Yuan $Y$ and Pan CW: Ethnic variations in pterygium in a rural population in southwestern China: The Yunnan minority eye studies. Ophthalmic Epidemiol 23: 116-121, 2016.

5. Coroneo MT, Di Girolamo N and Wakefield D: The pathogenesis of pterygia. Curr Opin Ophthalmol 10: 282-288, 1999.

6. Threlfall TJ and English DR: Sun exposure and pterygium of the eye: a dose-response curve. Am J Ophthalmol 128: 280-287, 1999.

7. Chui J, Di Girolamo N, Wakefield D and Coroneo MT: The pathogenesis of pterygium: current concepts and their therapeutic implications. Ocul Surf 6: 24-43, 2008.

8. Anguria P, Kitinya J, Ntuli S and Carmichael T: The role of heredity in pterygium development. Int J Ophthalmol 7: 563-573, 2014.

9. Bianchi E, Scarinci F, Grande C, Plateroti R, Plateroti P, Plateroti AM, Fumagalli L, Capozzi P, Feher J and Artico M: Immunohistochemical profile of VEGF, TGF- $\beta$ and $\mathrm{PGE}_{2}$ in human pterygium and normal conjunctiva: experimental study and review of the literature. Int J Immunopathol Pharmacol 25: 607-615, 2012

10. Young CH, Lo YL, Tsai YY, Shih TS, Lee H and Cheng YW: CYP1A1 gene polymorphisms as a risk factor for pterygium. Mol Vis 16: 1054-1058, 2010.

11. Kria L, Ohira A and Amemiya T: Growth factors in cultured pterygium fibroblasts: immunohistochemical and ELISA analysis. Graefes Arch Clin Exp Ophthalmol 236: 702-708, 1998.

12. Powers MR, Qu Z, O'Brien B, Wilson DJ, Thompson JE and Rosenbaum JT: Immunolocalization of bFGF in pterygia: association with mast cells. Cornea 16: 545-549, 1997.

13. Lee DH, Cho HJ, Kim JT, Choi JS and Joo CK: Expression of vascular endothelial growth factor and inducible nitric oxide synthase in pterygia. Cornea 20: 738-742, 2001.

14. Chen JK, Tsai RJ and Lin SS: Fibroblasts isolated from human pterygia exhibit transformed cell characteristics. In Vitro Cell Dev Biol Anim 30A: 243-248, 1994.

15. Maheshwari RK, Singh AK, Gaddipati J and Srimal RC: Multiple biological activities of curcumin: a short review. Life Sci 78: 2081-2087, 2006

16. Zhang N, Li H, Jia J and He M: Anti-inflammatory effect of curcumin on mast cell-mediated allergic responses in ovalbumin-induced allergic rhinitis mouse. Cell Immunol 298: 88-95, 2015.

17. Kunnumakkara AB, Anand $\mathrm{P}$ and Aggarwal BB: Curcumin inhibits proliferation, invasion, angiogenesis and metastasis of different cancers through interaction with multiple cell signaling proteins. Cancer Lett 269: 199-225, 2008.

18. Collaborative Ocular Melanoma Study Group: The COMS randomized trial of iodine 125 brachytherapy for choroidal melanoma: $\mathrm{V}$. Twelve-year mortality rates and prognostic factors: COMS report No. 28. Arch Ophthalmol 124: 1684-1693, 2006.

19. Bimonte S, Barbieri A, Palma G, Rea D, Luciano A, D'Aiuto M, Arra C and Izzo F: Dissecting the role of curcumin in tumour growth and angiogenesis in mouse model of human breast cancer. BioMed Res Int 2015: 878134, 2015.

20. Khan N and Mukhtar H: Dietary agents for prevention and treatment of lung cancer. Cancer Lett 359: 155-164, 2015.

21. Chen A, Xu J and Johnson AC: Curcumin inhibits human colon cancer cell growth by suppressing gene expression of epidermal growth factor receptor through reducing the activity of the transcription factor Egr-1. Oncogene 25: 278-287, 2006.

22. Gupta SC, Patchva S and Aggarwal BB: Therapeutic roles of curcumin: lessons learned from clinical trials. AAPS J 15: 195-218, 2013.

23. Amin AR, Haque A, Rahman MA, Chen ZG, Khuri FR and Shin DM: Curcumin induces apoptosis of upper aerodigestive tract cancer cells by targeting multiple pathways. PLoS One 10: e0124218, 2015.

24. Shi M, Cai Q, Yao L, Mao Y, Ming Y and Ouyang G: Antiproliferation and apoptosis induced by curcumin in human ovarian cancer cells. Cell Biol Int 30: 221-226, 2006.

25. Hong JH, Ahn KS, Bae E, Jeon SS and Choi HY: The effects of curcumin on the invasiveness of prostate cancer in vitro and in vivo. Prostate Cancer Prostatic Dis 9: 147-152, 2006.

26. Lu C, Song E, Hu DN, Chen M, Xue C, Rosen R and McCormick SA: Curcumin induces cell death in human uveal melanoma cells through mitochondrial pathway. Curr Eye Res 35: 352-360, 2010.

27. Zhang M, Bian F, Wen C and Hao N: Inhibitory effect of curcumin on proliferation of human pterygium fibroblasts. J Huazhong Univ Sci Technolog Med Sci 27: 339-342, 2007. 
28. Yang SF, Lin CY, Yang PY, Chao SC, Ye YZ and Hu DN: Increased expression of gelatinase (MMP-2 and MMP-9) in pterygia and pterygium fibroblasts with disease progression and activation of protein kinase C. Invest Ophthalmol Vis Sci 50: 4588-4596, 2009.

29. Ribatti D, Nico B, Perra MT, Maxia C, Piras F, Murtas D, Crivellato E and Sirigu P: Correlation between NGF/TrkA and microvascular density in human pterygium. Int J Exp Pathol 90: 615-620, 2009.

30. Dos Reis GM, de P R Júnior A, E Silva KS, Rodrigues DA, Gomes MC, Martins JV, da Costa IR, Freitas GA and Moura KK: Pterygium in patients from Goiânia, Goiás, Brazil. Genet Mol Res 14: 6182-6188, 2015.

31. Shehzad A, Lee J and Lee YS: Curcumin in various cancers. Biofactors 39: 56-68, 2013.

32. Witkin JM and Li X: Curcumin, an active constiuent of the ancient medicinal herb Curcuma longa L.: some uses and the establishment and biological basis of medical efficacy. CNS Neurol Disord Drug Targets 12: 487-497, 2013.

33. Li Y and Zhang T: Targeting cancer stem cells by curcumin and clinical applications. Cancer Lett 346: 197-205, 2014.

34. Prasad S, Gupta SC, Tyagi AK and Aggarwal BB: Curcumin, a component of golden spice: from bedside to bench and back. Biotechnol Adv 32: 1053-1064, 2014.

35. Rahmani AH, Al Zohairy MA, Aly SM and Khan MA: Curcumin: a potential candidate in prevention of cancer via modulation of molecular pathways. Biomed Res Int 2014: 761608, 2014.

36. Han SS, Chung ST, Robertson DA, Ranjan D and Bondada S: Curcumin causes the growth arrest and apoptosis of B cell lymphoma by downregulation of egr-1, c-myc, bcl-XL, NF- $\kappa \mathrm{B}$, and p53. Clin Immunol 93: 152-161, 1999.

37. Mukherjee Nee Chakraborty S, Ghosh U, Bhattacharyya NP, Bhattacharya RK, Dey S and Roy M: Curcumin-induced apoptosis in human leukemia cell HL-60 is associated with inhibition of telomerase activity. Mol Cell Biochem 297: 31-39, 2007.
38. Shishodia S, Chaturvedi MM and Aggarwal BB: Role of curcumin in cancer therapy. Curr Probl Cancer 31: 243-305, 2007.

39. Li J, Zhang D, Stoner GD and Huang C: Differential effects of black raspberry and strawberry extracts on BaPDE-induced activation of transcription factors and their target genes. Mol Carcinog 47: 286-294, 2008.

40. Coussens LM and Werb Z: Matrix metalloproteinases and the development of cancer. Chem Biol 3: 895-904, 1996.

41. Tsai CH, Chiang YC, Chen HT, Huang PH, Hsu HC and Tang CH: High glucose induces vascular endothelial growth factor production in human synovial fibroblasts through reactive oxygen species generation. Biochim Biophys Acta 1830: 2649-2658, 2013.

42. Liu W, Sha X, Wen Y, Zhao W, Luo W and Hua Z: Effect of Avastin on the migration and invasion of pterygium fibroblasts. Eye Sci 29: 214-218, 2014.

43. Hosseini H, Nejabat M and Khalili MR: Bevacizumab (Avastin) as a potential novel adjunct in the management of pterygia. Med Hypotheses 69: 925-927, 2007.

44. Bahar I, Yeung SN, Sella R and Slomovic A: Anterior segment uses of bevacizumab. Curr Opin Ophthalmol 23: 303-316, 2012.

45. Hu A, Huang JJ, Jin XJ, Li JP, Tang YJ, Huang XF, Cui HJ, $\mathrm{Xu} \mathrm{WH}$ and Sun GB: Curcumin suppresses invasiveness and vasculogenic mimicry of squamous cell carcinoma of the larynx through the inhibition of JAK-2/STAT-3 signaling pathway. Am J Cancer Res 5: 278-288, 2014.

46. Sun ZJ, Chen G, Zhang W, Hu X, Liu Y, Zhou Q, Zhu LX and Zhao YF: Curcumin dually inhibits both mammalian target of rapamycin and nuclear factor- $\kappa \mathrm{B}$ pathways through a crossed phosphatidylinositol 3-kinase/Akt/I $\kappa \mathrm{B}$ kinase complex signaling axis in adenoid cystic carcinoma. Mol Pharmacol 79: 106-118, 2011. 